RESEARCH ARTICLE

\title{
Influence of different media, medium strength and carbon sources on adventitious shoot cultures and production of bacoside A in Bacopa monnieri (L.)
}

\section{Poornananda Madhava Naik ${ }^{1}$, Manoj Godbole ${ }^{2, *}$, Praveen Nagella ${ }^{3}$ and Hosakatte Niranjana Murthy ${ }^{4}$}

${ }^{I}$ Department of Agricultural Biotechnology, College of Agricultural and Food Sciences, King Faisal University, P.O. Box 420, Al-Hassa 31982, Saudi Arabia.

${ }^{2 *}$ PG Department of Biotechnology, Sri Dharmasthala Manjunatheshwara College (Autonomous), Ujire 574240, India.

${ }^{3}$ Department of Botany, Christ University, Hosur Road, Bengaluru - 560029, India.

${ }^{4}$ PG Department of Botany, Karnatak University, Dharwad - 560003, India

\begin{abstract}
Bacopa monnieri (L.) Wettst. (Plantaginaceae), commonly known as Brahmi, is used in Ayurveda as a medicinal herb, found throughout the Indian subcontinent in wet, damp and marshy areas. The herb yields pharmaceutically active compounds called bacosides. The current investigation was carried out to assess the potential for increasing biomass and the concentration of bacoside $\mathrm{A}$ from the in vitro regenerated shoots in different media (MS, B5, NN and N6), the strength of the MS medium $(0.25,0.50,0.75,1.0,1.50$ and $2.0 \mathrm{X})$ and carbon source [sucrose, glucose, fructose, maltose, sucrose + glucose $(1: 1)$, sucrose + maltose $(1: 1)$, glucose + fructose $(1: 1)$, glucose + maltose $(1: 1)$, fructose + sucrose $(1: 1)$ and fructose + maltose $(1: 1)]$. All the culture media were supplemented with $2 \mathrm{mg} / \mathrm{L}$ Kinetin (Kin) at $\mathrm{pH}$ 5.8. High performance liquid chromatography (HPLC) was used to determine the bacoside A content from the regenerated shoots. Optimum number of adventitious shoots (70.75 shoots per explant), fresh weight (2.344 g), dry weight (0.166 g) and bacoside A content $(13.052 \mathrm{mg} / \mathrm{g} \mathrm{DW})$ were obtained from the cultures grown in the MS medium. Bacoside A production was highest in the shoots grown in the glucose + fructose combination $(15.588$ $\mathrm{mg} / \mathrm{g}$ DW) among the different carbon sources tested. These findings suggest that $B$. monnieri culture requires full strength $\mathrm{MS}$ medium and a moderate level of sucrose. The present study is useful to obtain optimum production of biomass and bacoside $\mathrm{A}$ from the in vitro regenerated shoots of $B$. monnieri.
\end{abstract}

Keywords: Adventitious shoots; Bacopa monnieri; Bacoside A; Biomass; Carbon source.

\section{INTRODUCTION}

Bacopa monnieri (L.) Wettst. (Plantaginaceae), commonly known as Brahmi, is a medicinal herb, found throughout the Indian subcontinent in wet, damp and marshy areas. It is an important Ayurvedic medicine for the improvement of intelligence, memory and the revitalization of sensory organs (Sivarajan and Balachandran, 1994; Pravina et al., 2007). The Brahmi extract is known to possess anticancer and antioxidant properties (Elangovan et al., 1995; Tripathi et al., 1996). The nootropic activity of the extract has been attributed to the presence of two saponins, namely bacoside $\mathrm{A}$ and bacoside $\mathrm{B}$, of which the former is more important (Singh et al., 1988; Dhawan and Singh, 1996; Singh et al., 1997). In addition to memory boosting activity, it is also claimed to be useful in the treatment of cardiac, respiratory and of neuropharmocological disorders like insomnia, insanity, depression, psychosis, epilepsy and stress (Russo and Borrelli, 2005). It was reported to possess antiinflammatory, analgesic, antipyretic, sedative, free radical scavenging and also antilipidperoxidative activities (Russo and Borrelli, 2005). Increasing the bacoside A content in $B$. monnieri would have a number of benefits in pharmaceutical and industrial applications.

Plant cell and organ cultures are promising technologies to obtain plant-specific valuable metabolites (Verpoorte et al., 2002). Cell and organ cultures have a higher rate of metabolism than field grown plants because the initiation of cell and organ growth in culture leads to the fast proliferation of cells/organs and to a condensed biosynthetic cycle (Rao and Ravishankar, 2002). Further, plant cell/organ cultures are not limited by environmental, ecological and climatic 
conditions, and cells/organs can thus proliferate at higher growth rates than whole plant in cultivation. Several biotechnological advances have been developed in tissue culture that improve secondary metabolite production such as optimization of cultural conditions, selection of high-producing strains of lines, precursor feeding, elicitation, metabolic engineering, transformed root cultures, micropropagation, and bioreactor cultures, among others (Sarin, 2005; Murthy et al., 2014). Although carbohydrates are of prime importance for in vitro organogenesis, carbon metabolism in vitro is still not clearly understood (Kozai, 1991). It is well established that carbohydrate requirements depend upon the stage of culture and may show differences according to the species (Thompson and Thorpe, 1987). In vitro shoot regeneration methods have been established in Brahmi (Praveen et al., 2009; Naik et al., 2010, 2011, 2014). However effects of different media, medium strength and carbon sources on biomass accumulation and production of secondary metabolite in regenerated shoots have not been worked out. The present work reports the effects of different media, medium strength and carbon source on shoot regeneration, biomass accumulation from leaf explants of $B$. monnieri and production of bacoside $\mathrm{A}$ in regenerated shoots.

\section{MATERIALS AND METHODS}

\section{Plant material and establishment of culture}

Actively growing adventitious shoots of $B$. monnieri (L.) had been cultured for 2 months on Murashige and Skoog (MS, 1962) medium supplemented with $0.8 \%$ agar, $2 \%$ sucrose $(w / v)$ and $2 \mathrm{mg} / \mathrm{L}$ Kin at $\mathrm{pH} 5.8$ in the plant tissue culture laboratory, Department of Botany, Karnatak University, Dharwad, India (Praveen et al., 2009). From the in vitro adventitious shoots, leaf sections $(5 \times 5 \mathrm{~mm})$ were cultured (abaxial surface down) into magenta boxes (Himedia, India) each containing $50 \mathrm{~mL}$ of Murashige and Skoog (MS) agar (0.8\%) medium supplemented with $2 \mathrm{mg} / \mathrm{L}$ Kin. Different media such as MS, Gamborg's (B5) 1968, Nitsch and Nitsch (NN) 1969 and Chu's (N6) 1978, as well as various strengths of MS medium $(0.25,0.50,0.75,1.0$, 1.50 and 2.0X) were tested depending on the objective of the experiment. In another set of experiments the effect of different carbon sources like sucrose, glucose, fructose, maltose, sucrose + glucose $(1: 1)$, sucrose + maltose $(1: 1)$, glucose + fructose $(1: 1)$, glucose + maltose $(1: 1)$, fructose + sucrose (1:1) and fructose + maltose (1:1) were studied for the shoot regeneration, biomass accumulation and bacoside A production. All cultures were incubated in the growth chambers at $25 \pm 1^{\circ} \mathrm{C}$, with a $16 \mathrm{~h}$ photoperiod $\left(40 \mu \mathrm{mol} \mathrm{m} \mathrm{m}^{-2} \mathrm{~s}^{-1}\right)$ provided by $40-\mathrm{W}$ fluorescent lamps (Philips, Kolkata, India). After one month, the explants were subcultured to the same media concentration from where they have come from. After two months of culture, the explants were examined and number of adventitious shoots per explant, fresh weight of shoot clusters along with explant was recorded. Shoot clusters along with original explant were collected and oven dried at $60^{\circ} \mathrm{C}$ for one day and dry weight was recorded.

\section{Extraction and HPLC analysis}

Extraction and HPLC analysis of bacoside A were carried out by following the method of Murthy et al. (2006) with some modifications. Thirty milligram of powdered plant material was extracted in $25 \mathrm{~mL}$ of $70 \%$ methanol by heat refluxing for 45 minutes and filtered through $0.45 \mu \mathrm{m}$ membrane filters. The bacoside fractions were analysed using Shimadzu HPLC system equipped with Phenomenex C18, $5 \mu \mathrm{m}$ $(4.6 \times 250 \mathrm{~mm})$ column, LC10AT VP lamps, SCL-10AVP system controller, SIL-10 AD VP auto injector, SPD-M10 AVP photodiode array detector. The mobile phase was a mixture of acetonitrile and water $(60: 40, \mathrm{v} / \mathrm{v})$ at a flow rate of $1 \mathrm{~mL} / \mathrm{min}$ and column temperature was maintained at $30^{\circ} \mathrm{C}$. The detection wavelength was set at $205 \mathrm{~nm}$. The injection volume was 20 $\mu \mathrm{L}$. The chromatography system was equilibrated by the mobile phase. The standard bacoside A was purchased from Chromadex (Laguna Hill, CA, USA). The standard bacoside A chromatogram was used to quantify the concentrations of bacoside $\mathrm{A}$ in B. monnieri extracts.

\section{Statistical analysis}

All the experiments were conducted with a minimum of 12 replicates and the experiment was repeated three times. The data were subjected to analysis of variance (ANOVA), and comparisons between the mean values of treatments were made by the least significant difference (Duncan post hoc) test $(P \leq 0.05)$. Statistical analyses were performed using the 
SPSS statistical package (SPSS ver. 17, SPSS Inc. Chicago, USA).

\section{RESULTS}

\section{Influence of different media}

In the present study, highest number of shoots (70.75 shoots per explant), fresh weight (2.344 $\mathrm{g})$, dry weight $(0.166 \mathrm{~g})$ and bacoside A content (13.052 $\mathrm{mg} / \mathrm{g} \mathrm{DW})$ were obtained in the MS medium, whereas B5, NN and N6 medium showed lesser quantities of the above parameters (Table 1) (Figure 1). Optimum number of shoots (38.75, 45.25 and 44.50 shoots per explant), fresh weight $(1.423,1.214$ and $1.172 \mathrm{~g})$, dry weight $(0.096,0.098$ and $0.083 \mathrm{~g})$ and bacoside A content (12.205, 9.346 and $12.162 \mathrm{mg} / \mathrm{g} \mathrm{DW})$ were obtained in $\mathrm{B} 5, \mathrm{NN}$ and $\mathrm{N} 6$ medium respectively.

\section{Influence of MS medium strength}

We have tested the effect of various MS medium strength on adventitious shoot regeneration, biomass and bacoside A accumulation from leaf explants of B. monnieri. Our study showed that highest number of shoots (71.00 shoots per explant), fresh weight $(2.390 \mathrm{~g})$, dry weight $(0.164 \mathrm{~g})$ and bacoside A content $(13.092 \mathrm{mg} / \mathrm{g}$ DW) were obtained in full-strength MS medium (Table 2) (Figure 2). Interestingly, explants grown in $1.5 \mathrm{X}$ strength $\mathrm{MS}$ medium though produced lowest number of shoots (8.50 shoots per explant), fresh weight $(0.755 \mathrm{~g})$ and dry weight $(0.055 \mathrm{~g})$ it also accumulated higher bacoside A content $(12.97 \mathrm{mg} / \mathrm{g} \mathrm{DW})$. Double strength (2.0X) MS medium also showed higher concentrations of bacoside A $(12.582 \mathrm{mg} / \mathrm{g} \mathrm{DW})$ without producing much of the shoot (17.25 shoots per explant). Remaining media strength i.e. $0.25,0.5$ and $0.75 \mathrm{X}$ produced $25.75,58.50$ and 52.25 shoots per explant respectively and accumulated bacoside $\mathrm{A}$ at the intermediate levels (7.403, 9.781 and $11.448 \mathrm{mg} / \mathrm{g}$ DW respectively).

Table 1:The effect of different media on adventitious shoot regeneration and biomass accumulation from leaf explants of Bacopa monnierix xData were collected over two months of culture. Values represent the mean \pm SE. Mean values following the same letter within columns are not significantly different, according to Duncan's multiple range $(\mathrm{p} \leq 0.05)$ test.

\begin{tabular}{cccc}
\hline Media & Mean no. shoot per explants & Mean fresh weight $(\mathbf{g})$ & Mean dry weight $(\mathbf{g})$ \\
\hline MS & $70.75 \pm 1.376 \mathrm{a}$ & $2.344 \pm 0.038 \mathrm{a}$ & $0.166 \pm 0.001 \mathrm{a}$ \\
B5 & $38.75 \pm 0.629 \mathrm{c}$ & $1.423 \pm 0.005 \mathrm{~b}$ & $0.096 \pm 0.003 \mathrm{~b}$ \\
NN & $45.25 \pm 0.629 \mathrm{~b}$ & $1.214 \pm 0.015 \mathrm{c}$ & $0.098 \pm 0.001 \mathrm{~b}$ \\
N6 & $44.50 \pm 1.892 \mathrm{~b}$ & $1.172 \pm 0.002 \mathrm{c}$ & $0.083 \pm 0.001 \mathrm{c}$ \\
\hline
\end{tabular}

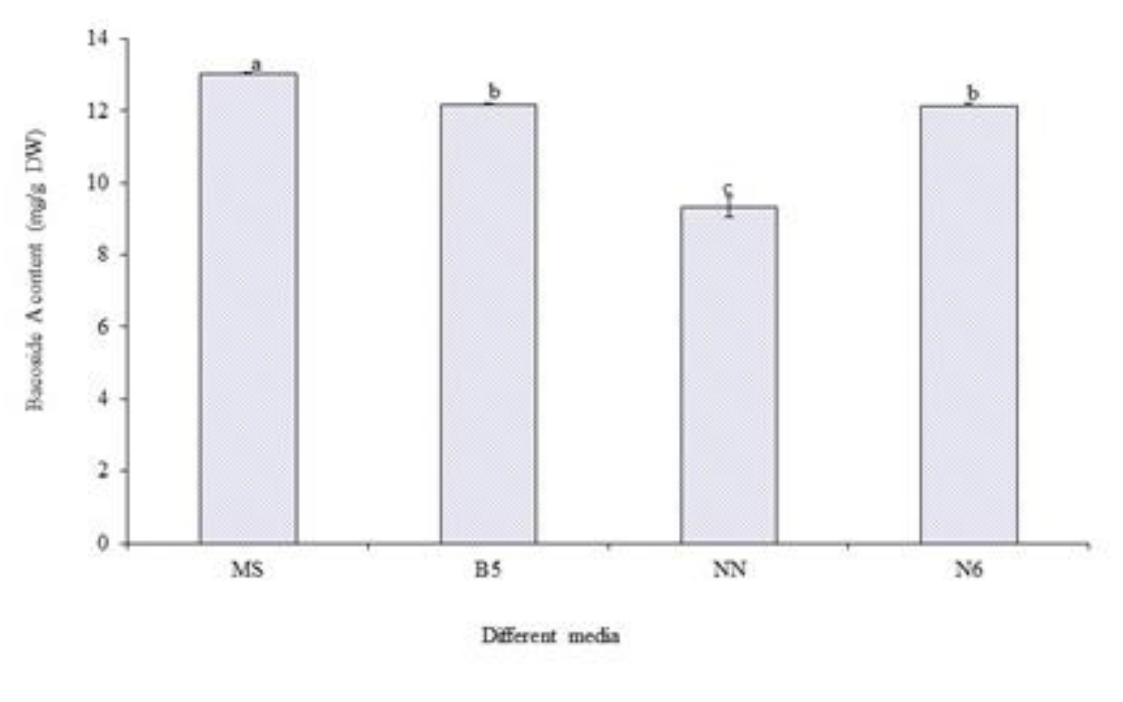

Figure 1: Effect of different media on bacoside A accumulation from leaf explants of B. monnieri cultured for two months, supplemented with $2 \mathrm{mg} / \mathrm{L}$ Kin and $2 \%$ sucrose at $\mathrm{pH}$ 5.8. Data were collected over two months of culture. Bars represent the standard errors, mean values following the same letter are not significantly different, according to Duncan's multiple range $(p \leq 0.05)$ test . 
Table 2: The effect of various medium strength on adventitious shoot regeneration and biomass accumulation from leaf explants of Bacopa monnieri ${ }^{\mathrm{x}}$

${ }^{x}$ Data were collected over two months of culture. Values represent the mean \pm SE. Mean values following the same letter within columns are not significantly different, according to Duncan's multiple range $(p \leq 0.05)$ test.

\begin{tabular}{cccc}
\hline $\begin{array}{c}\text { Media } \\
\text { Strength }(\mathbf{X})\end{array}$ & $\begin{array}{c}\text { Mean no. shoot per } \\
\text { explants }\end{array}$ & Mean fresh weight $(\mathbf{g})$ & Mean dry weight $(\mathbf{g})$ \\
\hline 0.25 & $25.75 \pm 0.381 \mathrm{~d}$ & $1.516 \pm 0.021 \mathrm{~d}$ & $0.116 \pm 0.003 \mathrm{c}$ \\
0.5 & $58.50 \pm 0.288 \mathrm{~b}$ & $2.226 \pm 0.070 \mathrm{~b}$ & $0.160 \pm 0.001 \mathrm{ab}$ \\
0.75 & $52.25 \pm 0.629 \mathrm{c}$ & $2.088 \pm 0.049 \mathrm{c}$ & $0.156 \pm 0.001 \mathrm{~b}$ \\
1.0 & $71.00 \pm 1.527 \mathrm{a}$ & $2.390 \pm 0.034 \mathrm{a}$ & $0.164 \pm 0.002 \mathrm{a}$ \\
1.5 & $8.50 \pm 0.288 \mathrm{f}$ & $0.755 \pm 0.013 \mathrm{f}$ & $0.055 \pm 0.003 \mathrm{e}$ \\
2.0 & $17.25 \pm 0.946 \mathrm{e}$ & $1.250 \pm 0.004 \mathrm{e}$ & $0.105 \pm 0.002 \mathrm{~d}$ \\
\hline
\end{tabular}

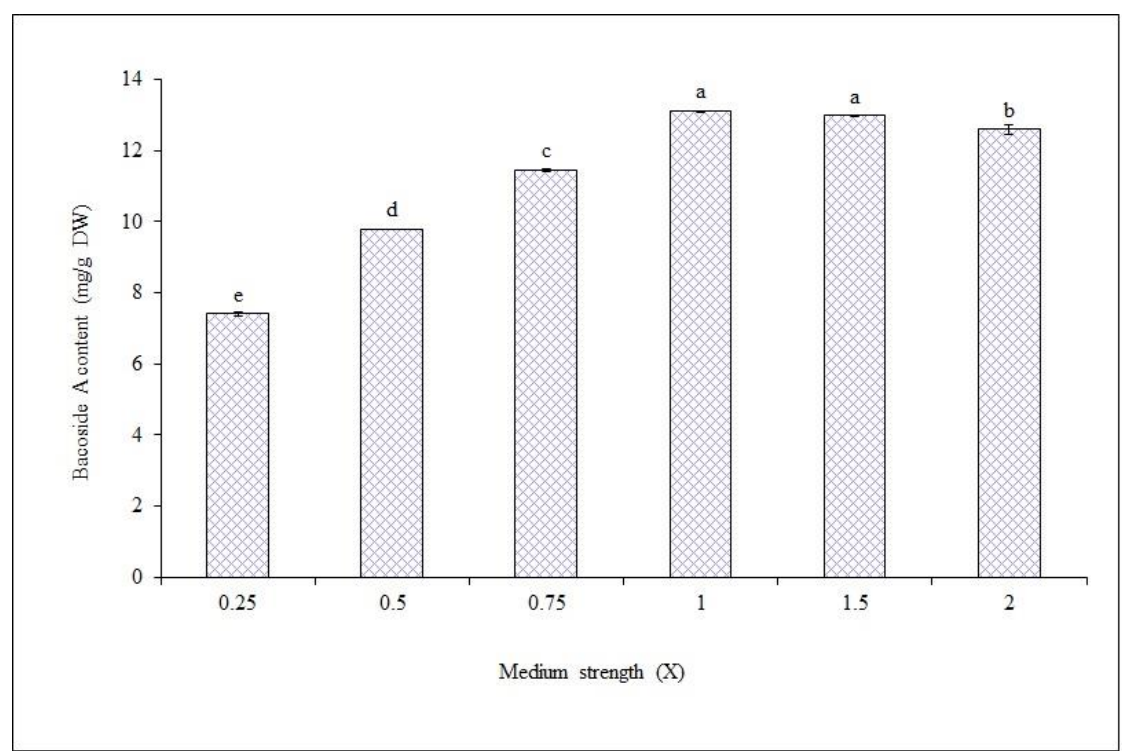

Figure 2: Effect of various medium strength on bacoside A accumulation from leaf explants of B. monnieri cultured for two months on MS medium supplemented with $2 \mathrm{mg} / \mathrm{L}$ Kin and $2 \%$ sucrose at $\mathrm{pH}$ 5.8. Data were collected over two months of culture. Bars represent the standard errors, mean values following the same letter are not significantly different, according to Duncan's multiple range $(p \leq 0.05)$ test.

\section{Influence of different carbon sources}

In the present study, the effect of different carbon sources like sucrose, glucose, fructose, maltose, sucrose + glucose $(1: 1)$, sucrose + maltose $(1: 1)$, glucose + fructose $(1: 1)$, glucose + maltose $(1: 1)$, fructose + sucrose $(1: 1)$ and fructose + maltose (1:1) were studied for the adventitious shoot regeneration, biomass accumulation and bacoside A production. Sucrose induced an optimum number of adventitious shoots (70.75) from the explants followed by sucrose + maltose, fructose + maltose and glucose + fructose (64.00, 63.50 and 61.75 shoots per explant respectively) remaining carbohydrates treated leaf explants produced a lesser number of shoots (Table 3 ). Sucrose also induced maximum biomass (fresh weight and dry weight). Bacoside A production was highest in the glucose + fructose combination (15.588 mg/g DW; Figure 3) followed by sucrose + maltose $(14.468 \mathrm{mg} / \mathrm{g}$ DW) and fructose alone supplemented medium $(14.186 \mathrm{mg} / \mathrm{g} \mathrm{DW})$. In glucose + maltose combination, both adventitious shoot production and bacoside A accumulation was the lowest among all the tested combinations (19.00 shoots per explant; $10.940 \mathrm{mg} / \mathrm{g} \mathrm{DW}$ ). 
Table 3: The effect of different carbon sources on adventitious shoot regeneration and biomass accumulation from leaf explants of Bacopa monnieri ${ }^{\mathrm{x}}$

${ }^{\mathrm{x}}$ Data were collected over two months of culture. Values represent the mean \pm SE. Mean values following the same letter within columns are not significantly different, according to Duncan's multiple range $(p \leq 0.05)$ test.

\begin{tabular}{cccc}
\hline Carbon sources (2\%) & Mean no. shoot per explants & Mean fresh weight $(\mathbf{g})$ & Mean dry weight $(\mathbf{g})$ \\
\hline Sucrose & $70.75 \pm 1.376 \mathrm{a}$ & $2.272 \pm 0.008 \mathrm{a}$ & $0.165 \pm 0.002 \mathrm{a}$ \\
Glucose & $39.25 \pm 1.842 \mathrm{e}$ & $1.178 \pm 0.010 \mathrm{e}$ & $0.091 \pm 0.001 \mathrm{~d}$ \\
Fructose & $52.75 \pm 1.181 \mathrm{~d}$ & $1.170 \pm 0.003 \mathrm{e}$ & $0.114 \pm 0.001 \mathrm{c}$ \\
Maltose & $28.25 \pm 1.181 \mathrm{f}$ & $0.510 \pm 0.008 \mathrm{~g}$ & $0.085 \pm 0.003 \mathrm{~d}$ \\
Sucrose + Glucose & $36.75 \pm 1.520 \mathrm{e}$ & $1.342 \pm 0.013 \mathrm{~d}$ & $0.093 \pm 0.002 \mathrm{~d}$ \\
Sucrose + Maltose & $64.00 \pm 1.527 \mathrm{~b}$ & $1.860 \pm 0.010 \mathrm{c}$ & $0.113 \pm 0.003 \mathrm{c}$ \\
Glucose + Fructose & $61.75 \pm 1.145 \mathrm{bc}$ & $2.048 \pm 0.028 \mathrm{~b}$ & $0.125 \pm 0.003 \mathrm{~b}$ \\
Glucose + Maltose & $19.00 \pm 0.577 \mathrm{~g}$ & $0.894 \pm 0.012 \mathrm{f}$ & $0.066 \pm 0.003 \mathrm{e}$ \\
Fructose+ Sucrose & $58.25 \pm 1.842 \mathrm{c}$ & $1.185 \pm 0.009 \mathrm{e}$ & $0.091 \pm 0.002 \mathrm{~d}$ \\
Fructose+ Maltose & $63.50 \pm 1.322 \mathrm{~b}$ & $2.031 \pm 0.024 \mathrm{~b}$ & $0.131 \pm 0.003 \mathrm{~b}$ \\
\hline
\end{tabular}

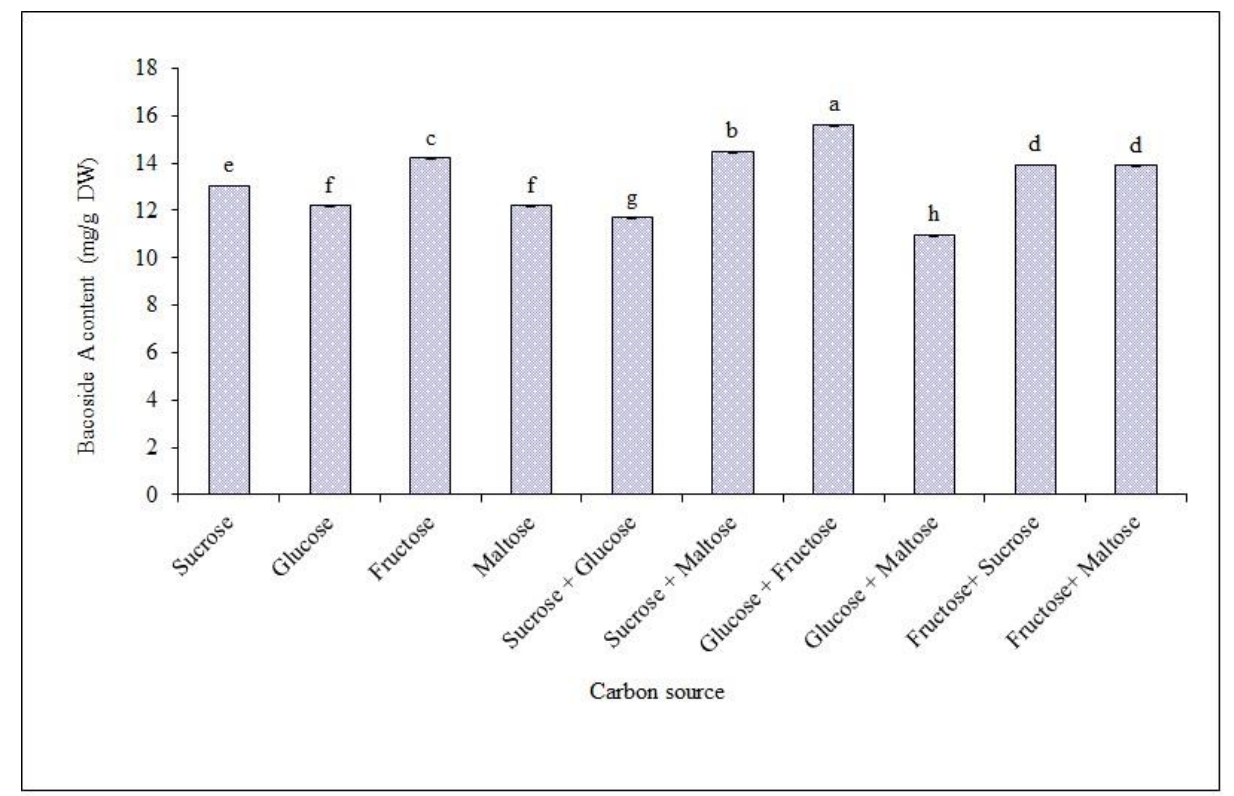

Figure 3: Effect of different carbon sources on bacoside A accumulation from leaf explants of B. monnieri cultured for two months on MS medium supplemented with $2 \mathrm{mg} / \mathrm{L} \mathrm{Kin} \mathrm{at} \mathrm{pH}$ 5.8. Data were collected over two months of culture. Bars represent the standard errors, mean values following the same letter are not significantly different, according to Duncan's multiple range $(p \leq 0.05)$ test.

\section{DISCUSSION}

The degree of growth, differentiation and metabolite accumulation varies considerably with the medium constitution (Bhaskaran and Jayabalan, 2005). Our results are corroborated with the observations made by Bhaskaran and Jayabalan, (2005) in Eclipta alba where the MS medium was superior over B5 and SH media for a number of adventitious shoot production. MS medium was shown to be more effective than other media by various investigators (Tefera and
Wannakrairoj, 2004; Gao et al., 1999; Komalavalli and Rao, 2000; Ndoye et al., 2003). As nitrogen is to be a constituent of plant cell components, its deficiency inhibits plant growth. Total nitrogen content and nitrate:ammonium is very critical in nitrogen nutrition (Ramage and Williams, 2002). The nitrate:ammonium ratio strongly influences the $\mathrm{pH}$ of the medium, which in turn determines the absorption of other nutrients (Tefera and Wannakrairoj, 2004). Since the MS medium possesses relatively higher 
nitrate:nitrogen, it could have exerted the profound effect on shoot growth of this plant species.

The optimum nutrient concentration is a critical determinant in controlling the growth of the cells/organs and the accumulation of secondary metabolites (Murthy et al., 2008). In contrast to our results, Wu et al., (2006) reported that half-strength MS medium was effective to enhance biomass accumulation and phenolic synthesis in adventitious roots culture of Echinacea angustifolia among varied strength MS (0.25-2.0X) media tested.

Different types of sugars (sucrose, fructose, maltose, sorbitol or glucose) used in the medium may affect biomass and secondary metabolite accumulation, and it is essential to work out suitable sugar combinations in the culture medium to obtain higher levels of secondary metabolites (Rao and Ravishankar, 2002). Contrary to our results, in Stevia rebaudiana, fructose performed well followed by sucrose, maltose and glucose in keeping shoot number constant (Preethi et al., 2011). Similar to our findings in Gymnema sylvestrae, sucrose was proved to be the best among various carbohydrate sources tested for inducing maximum number of shoots and gymnemic acid production (Praveen et al., 2011). Sucrose proved to be better for shoot proliferation than other carbon sources in micropropagation of several plant species such as Pogostemon cablin (Kumara et al., 2010) and Centella asiatica (Anwar et al., 2005).

Uptake and utilization of different sugars might vary with different plant cells as reported by Srinivasan et al. (1995) and might be due to enzyme systems present in them for preferential utilization. In B. monnieri shoot cultures $2 \%$ sucrose favoured biomass accumulation, whereas sucrose-free medium accumulated maximum amount of bacoside A content (Naik et al., 2010).

\section{CONCLUSIONS}

The present study of adventitious shoot cultures of B. Monnieri has demonstrated the influence of different media, media strength and type of carbohydrate used in biomass and secondary metabolite accumulation. The highest number of adventitious shoots, fresh weight, dry weight and the production of bacoside A content were recorded in the MS medium among the different media and media strengths tested. Of the various carbon sources used, the glucose + fructose combination influenced maximally for the bacoside A production at optimum levels. These findings suggest that $B$. monnieri culture requires full strength MS medium and a moderate level of sucrose. Our results are promising and can be extrapolated for the large scale production of bacoside A via tissue culture.

\section{ACKNOWLEDGMENTS}

This work was partially financed by Council of Scientific and Industrial Research [No. 38(1098)/04/EMR-II] and University Grants Commission under the Special Assistance Programme, New Delhi, India.

\section{REFERENCES}

Anwar, H.Md., Taslim, H.Md., Raihanali, Md., Rahman, S.M.M. (2005). Effect of different carbon sources on in vitro regeneration of Indian Penny worth (Centella asiatica L.). Pak. Journal of Biological Science 8(7), 963-965.

Baskaran, P. and Jayabalan, N. (2005). Role of basal media, carbon sources and growth regulators in micropropagation of eclipta alba - a valuable medicinal herb. KMITL Science Journal 5(2), 469-482.

Chu, C.C. (1978). The N6 medium and its applications to anther culture of cereal crops. In: Proceedings of the Symposium Plant Tissue Culture, Science Press, Beijing, pp. 43-50.

Dhawan, B.N. and Singh, H.K. (1996). Pharmacological studies on Bacopa monnieri, an ayurvedic nootropic agent. European Neuropsychopharmacology 6: 144.

Elangovan, V., Govindasamy, S., Ramamoorthy, N. and Balasubramanian. K. (1995). In vitro studies on the anticancer activity of Bacopa monnieri. Fitoterapia 66: 211-215.

Gamborg, O.L., Miller, R.A. and Ojima, K. (1968). Nutrient requirements of suspension cultures of soybean root cells. Experimental Cell Research 50: $151-158$.

Gao, S.L., Zhu, D.N., Cai, Z.H., Jiang, Y. and Xu, D.R., (1999). Organ culture of a precious Chinese medicinal plant-Fritillaria unibracteata. Plant Cell, Tissue and Organ Culture 59, 97-201.

Komalavalli, N. and Rao, M.V. (2000). In vitro Micropropagation of Gymnema sylvestre - A multipurpose medicinal plant. Plant Cell, Tissue and Organ Culture 61: 97-105.

Kozai, T. (1991). Micropropagation under photoautotrophic conditions. In: Debergh, P.C., Zimmerman, R.H., Ed. Micropropagation: Technology and application. Kluwer Academic Publishers, Dordrecht, pp. 447- 469. 
Kumara, S.M., Balasubramanya, S. and Anuradha, M. (2010). In vitro multiplication of patchouli through direct organogenesis. African Journal of Biotechnology 9(14): 2069-2075.

Murashige, T., Skoog, F. (1962). A revised medium for rapid growth and bioassays with tobacco tissue cultures. Physiologia Plantarum 15: 473 497.

Murthy, H.N., Lee, E.J. and Paek, K.Y. (2014). Production of secondary metabolites from cell and organ cultures: strategies and approaches for biomass improvement and metabolite accumulation. Plant Cell, Tissue and Organ Culture 118: 1-16.

Murthy, H.N., Hahn, E.J. and Paek, K.Y. (2008). Adventitious roots and secondary metabolism. Chinese Journal of Biotechnology 24: 711-716.

Murthy, P.B.S., Raju, V.R., Ramakrishna, T., Chakravarthy, M.S., Kumar, K.V., Kannababu, S. and Subbaraju, G.V. (2006). Estimation of twelve bacopa saponins in Bacopa monnieri extracts and formulations by high-performance liquid chromatography. Chemical and Pharmaceutical Bulletin 54: 907-911.

Naik P.M., Patil B.R., Kotagi K.S., Kazi A.M., Lokesh H. and Kamplikoppa S.G. (2014). Rapid one step protocol for in vitro regeneration of Bacopa monnieri (L.). Journal of Cell Tissue and Research 14(2): 4293-4296.

Naik, P.M., Manohar, S.H. and Murthy, H.N. (2011). Effects of macro elements and nitrogen source on biomass accumulation and bacoside A production from adventitious shoot cultures of Bacopa monnieri (L.). Acta Physiologiae Plantarum 33: 1553-1557.

Naik, P.M., Manohar, S.H., Praveen, N. and Murthy. H.N. (2010). Effects of sucrose and pH levels on in vitro shoot regeneration from leaf explants of Bacopa monnieri and accumulation of bacoside A in regenerated shoots. Plant Cell, Tissue and Organ Culture 100: 235-239.

Ndoye, M., Diallo, I. and Gassama D.Y.K. (2003). In vitro Multiplication of the semi-arid forest tree, Balanites aegyptiaca (L) Del. African Journal of. Biotechnology 2(11): 421-424.

Nitsch, J.P. and Nitsch, C. (1969). Haploid plants from pollen grains. Science 163: 85-87.

Praveen, N, Chung, I.M. and Murthy, H.N. (2011). In vitro production of gymnemic acid from cell suspension cultures of Gymnema sylvestre $\mathrm{R}$. Br. Engineering in Life Sciences 11(5), 347-350.

Praveen, N., Naik, P.M., Manohar, S.H., Nayeem, A. and Murthy, H.N. (2009). In vitro regeneration of brahmi shoots using semisolid and liquid cultures and quantitative analysis of bacoside A, Acta Physiologiae Plantarum 31: 723-728.

Pravina, K., Ravindra, K.R., Goudar, K.S., Vinod, D.R., Joshua, A.J., Wasim, P., Venkateswarlu, K., Saxena, V.S. and Amit, A. (2007). Safety evaluation of BacoMind ${ }^{\mathrm{TM}}$ in healthy volunteers: A phase I study. Phytomedicine 14: 301-308.

Preethi, D., Sridhar, T.M. and Naidu C.V. (2011). Carbohydrate concentration influences on in vitro plant regeneration in Stevia rebaudiana. Journal of Phytology 3(5): 61-64.

Rao, R.S., Ravishankar, G.A., 2002. Plant cell cultures:chemical factories of secondary metabolites. Biotechnology Advances 20: 101153.

Ramage, C.M. and Williams, R.R. (2002). Mineral nutrition and plant morphogenesis. In Vitro Cellular and Developmental Biology- Plant 38: 116-124.

Russo, A., Borrelli. F., 2005. Bacopa monniera, a reputed nootropic plant: an overview. Phytomedicine 12: 305-317.

Sarin, R. (2005). Useful metabolites from plant tissue cultures. Biotechnology 4: 79-93.

Singh, H.K. and Dhawan, B.N. (1997). Neurophychopharmacological effects of the Ayurvedic nootropic Bacopa monniera Linn. (Brahmi). Indian Journal of Pharmcology 29: 359-365.

Singh, H.K., Rastogi, R.P., Srimal, R.C. and Dhawan, B.N. (1988). Effect of bacoside A and B on the avoidance responses in rats. Phytotherapy Research 2: 70-74.

Sivarajan, V.V. and Balachandran, I. (1994). Ayurvedic Drugs and their Plant sources. Oxford and IBH Publishing Co., New Delhi, pp. 97-99.

Srinivasan, V., Pestchanker, L., Moser, S., Hirasuna, T.J., Taticek, R.A. and Shuler, M.L. (1995). Taxol production in bioreactors: Kinetics of biomass accumulation, nutrient uptake and taxol production by cell suspension of Taxus baccata. Biotechnology and Bioengineering 47: 666-676.

Tefera, W. and Wannakrairoj, S. (2004). Micropropagation of Krawan (Amomum krervanh Pierre ex Gagnep). Science Asia 30: 9-15.

Thompson, M. and Thorpe, T. (1987). Metabolic and Non-metabolic Roles of Carbohydrates. In: Bonga, J.M and Durzan, D.J., Ed. Cell and Tissue Culture in Forestry. Martinus Nijhoff Publishers, Dordrecht, pp. 89-112.

Tripathi, Y.B., Chaurasia, S., Tripathi, E., Upadhyaya, A. and Dubey, G.P. (1996). Bacopa monniera Linn. as an antitoxidant: mechanism of action. Indian Journal of Experimental Biology 34, 523526.

Verpoorte, R., Contin, A. and Memelink, J. (2002). Biotechnology for the production of plant secondary metabolites. Phytochemistry Reviews 1, 13-25

Wu, C.H., Dewir, Y.H., Hahn, E.J. and Paek, K.Y. (2006). Optimization of culturing conditions for the production of biomass and phenolics from adventitious roots of Echinacea angustifolia. Journal of Plant Biology 49: 193-194. 
Weerasinghe, A., Puvenendran, S., Wickramasinghe, A., Karunaratne, D. N., Wijesundara, S. Karunaratne, V. (2013). Potent bioactivities of the endemic Annonaceae heightens its dire conservation status. Journal of the National Science Foundation of Sri Lanka 41(4): 345-350.

Wermuth, C. G. (2003). The Practice of Medicinal Chemistry. Amsterdam, the Netherlands: Academic.
Youns, M., Hoheisel, J.D. and Efferth, T. (2010). Toxicogenomics for the prediction of toxicity related to herbs from traditional Chinese medicine. Planta Medica 76: 2019-2025.

Zhong, G. S. and Wan, F. (1999). An outline on the early pharmaceutical development before Galen. Chinese Journal of Medical History 29: 178-182. 